Piotr SZABLEWSKI ${ }^{1}$

\title{
BADANIA WPLYWU GLĘBOKOŚCI SKRAWANIA NA CHROPOWATOŚĆ POWIERZCHNI STOPU INCONEL 718 PODCZAS TOCZENIA WYKOŃCZENIOWEGO
}

\begin{abstract}
Celem badań było określenie wpływu głębokości skrawania podczas wytaczania otworu w materiale Inconel 718 na chropowatość powierzchni obrobionej. Zbadano również w porównywalnych warunkach uzyskane chropowatości powierzchni po toczeniu wzdłużnym i wytaczaniu. Otrzymane wyniki wskazują na sensowność stosowania mniejszych wartości głębokości skrawania, ze względu na szybsze zużycie ostrza skrawającego, na co ma bezpośredni wpływ ograniczone chłodzenie w strefie skrawania. Przy najmniej korzystnych warunkach podczas wytaczania ostrze szybciej ulega zużyciu, co powoduje pogorszenie jakości powierzchni obrobionej. Ograniczona ilość cieczy chłodząco-smarującej w strefie skrawania jest efektem kłębiących się wiórów, które w przypadku małych średnic obrabianych otworów trudno usunąć z obrabianego przedmiotu. Takie same parametry, jakie stosowano w próbie, gdzie uzyskano najwyższą wartość chropowatości, zastosowano podczas toczenia wzdłużnego. W tym przypadku wiór swobodnie spływający po obrabianej części nie ograniczał ilości dostarczanego chłodziwa w strefie skrawania, czego efektem było mniejsze zużycie ostrza oraz mniejsza wartość chropowatości powierzchni.
\end{abstract}

Słowa kluczowe: trwałość ostrza, mikronierówność, wióry

\section{Wprowadzenie}

Materiały typu Inconel, których głównym składnikiem stopowym jest nikiel (w zależności od rodzaju stopu mogą one zawierać od 50 do $75 \%$ tego pierwiastka) są bardzo szeroko stosowane w przemyśle lotniczym, m.in. na korpusy sprężarek, dyski turbin, wały główne, zawory wydechowe, obudowy łożysk, komory spalania (rys. 1). Ze względu na wysoką cenę tego materiału jest on stosowany w gorącej sekcji silnika lotniczego, gdzie wykorzystuje się jego zdolność do pracy w wysokich temperaturach, nawet do $750^{\circ} \mathrm{C}[1,5]$.

\footnotetext{
1 Autor do korespondencji/corresponding author: Piotr Szablewski, Pratt \& Whitney Kalisz / PWSZ Kalisz, ul. Elektryczna 4a, tel.: 667681866, e-mail: piotr.szablewski@pwk.com.pl

2 Tomasz Dobrowolski, Pratt \& Whitney, Kalisz, e-mail: tomasz.dobrowolski@pwk.com.pl

${ }^{3}$ Piotr Kieruj, Politechnika Poznańska, e-mail: piotr.kieruj@ put.poznan.pl
} 
Materiał ten jest często obiektem badań, lecz mimo licznych publikacji i coraz szerszej wiedzy na jego temat wykonywanie części wciąż nastręcza wielu problemów. Inconel 718 z powodu swoich właściwości, do których należą: skłonność do umacniania się, mała przewodność cieplna, duża twardość i skłonność do reakcji z narzędziem, jest trudny w obróbce. Firmy narzędziowe specjalizujące się w produkcji narzędzi do obróbki materiałów na osnowie niklu przyjmują trwałość ostrzy na poziomie 15-20 min. Trwałość ta jest w dużej mierze uzależniona od konfiguracji obrabianej części. W przypadku elementów cienkościennych podczas obróbki pojawiają się drgania, zatem trwałość ostrza jest jeszcze krótsza.

Badania dotyczące trwałości ostrzy, która w głównej mierze decyduje o jakości obrobionej powierzchni, są prowadzone dla ostrzy zarówno z powłokami przeciwzużyciowymi, jak i bez nich $[2,3,4]$.

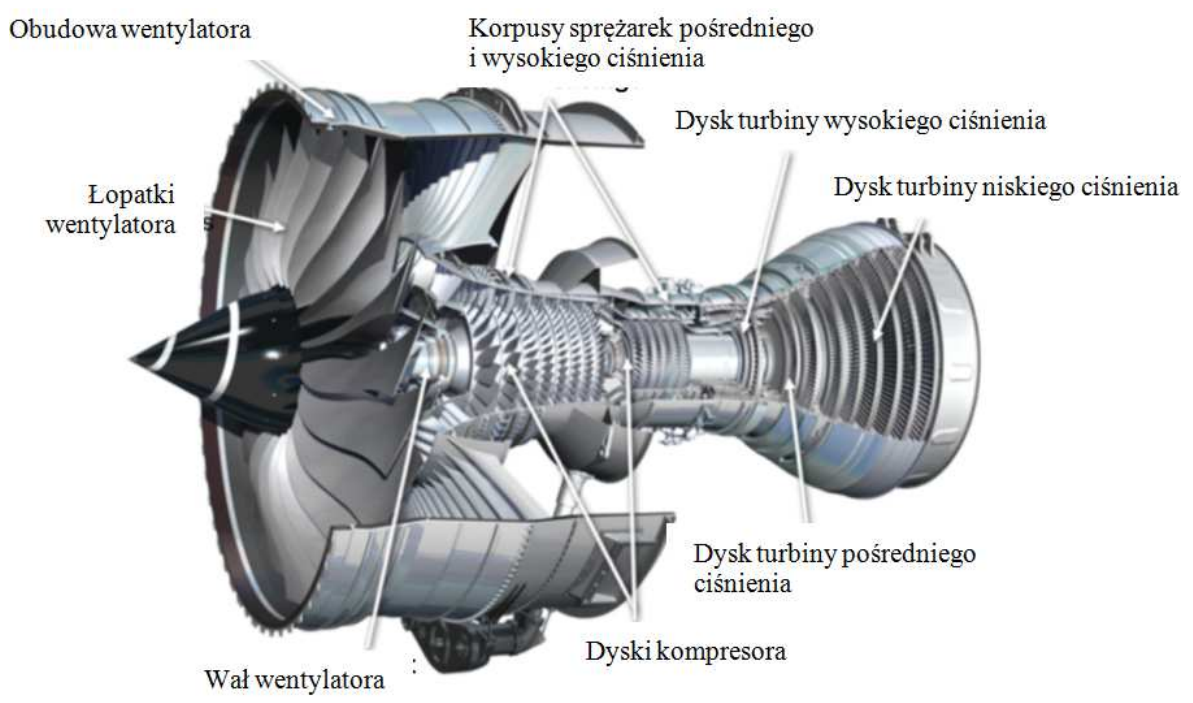

Rys. 1. Silnik turbowentylatorowy firmy Rolls-Royce XWB

Fig. 1. Rolls-Royce XWB turbofan engine

\section{Zakres i metodyka badań}

Toczenie wzdłużne powierzchni wewnętrznych i zewnętrznych przeprowadzono na tokarce TZD Chofum. Materiałem obrabianym był stop na osnowie niklu - Inconel 718. W badaniach zastosowano płytki skrawające DCGT 11T308 z powłoką przeciwzużyciową S05F nakładaną metodą CVD. W zależności od rodzaju obróbki - toczenie powierzchni walcowej zewnętrznej i wytaczanie zastosowano oprawki narzędziowe: SDJCL 2525 M11 i A32S-SDUCL 11 (kąt przystawienia główny $\kappa=95^{\circ}$ ). Chropowatość powierzchni rejestrowano na profilografometrze firmy Hommel Tester T1000. Mierzono parametry chropowatości $R a$. Próby przeprowadzono z użyciem cieczy chłodząco-smarującej. 
$\mathrm{W}$ badaniach zastosowano następujące parametry skrawania: $v_{c}=45 \mathrm{~m} / \mathrm{min}$, $f=0,1 \mathrm{~mm} /$ obr., $a_{p}=0,1-0,4 \mathrm{~mm}$.

\section{Wyniki badań i ich analiza}

Rysunek 2 przedstawia profile chropowatości poprzecznej powierzchni obrobionej po wytaczaniu płytką z węglika spiekanego S05F, który potwierdza zmiany mikrogeometrii ostrza w czasie skrawania $t$.

a)
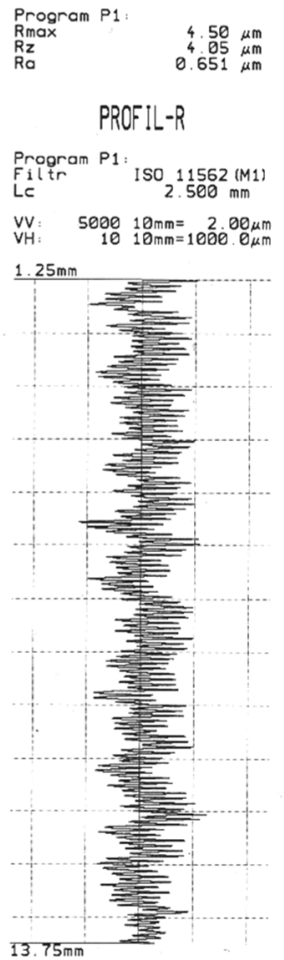

b)

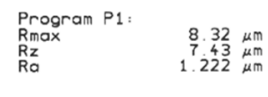

PROFIL-R

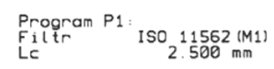

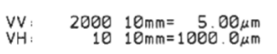

$1.25 \mathrm{~mm}$

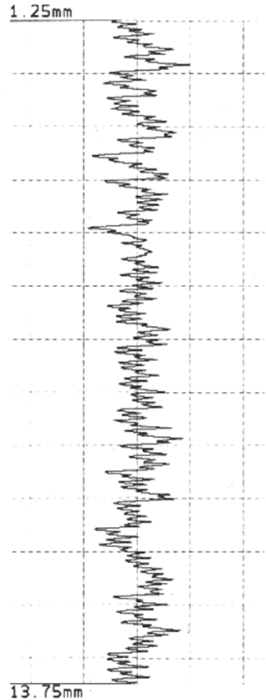

c)
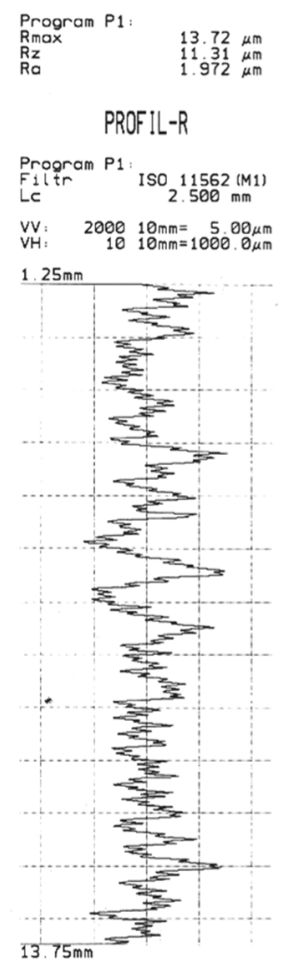

Rys. 2. Profile chropowatości poprzecznej powierzchni obrobionej po toczeniu: a) $t=30 \mathrm{~s}$, b) $t=3 \min 30 \mathrm{~s}$, c) $t=6 \min 30 \mathrm{~s} ; v_{c}=45 \mathrm{~m} / \mathrm{min}, f=0,1 \mathrm{~mm} / \mathrm{obr}$, $a_{p}=0,4 \mathrm{~mm}$

Fig. 2. Profiles of roughness of lateral surface after turning: a) $t=30 \mathrm{~s}, \mathrm{~b}) t=3$ $\min 30 \mathrm{~s}, \mathrm{c}) t=6 \mathrm{~min} 30 \mathrm{~s} ; v_{c}=45 \mathrm{~m} / \mathrm{min}, f=0.1 \mathrm{~mm} / \mathrm{rev} ., a_{p}=0.4 \mathrm{~mm}$

Na rysunku 3 przedstawiono wpływ czasu skrawania $t$ na wartości średnie $R a$ mikronierówności powierzchni obrobionej po toczeniu płytką z węglika spiekanego DCGT 11T308-UM S05F przy różnych głębokościach skrawania. Z badań wynika, że w początkowej fazie toczenia, niezależnie od wartości dosuwu, parametry mikronierówności są zbliżone. Po około 3,5 min pracy ostrza wartość parametru $R a$ dla głębokości skrawania $a_{p}=0,4 \mathrm{~mm}$ jest około 2 razy większa od 
wartości początkowej. Po kolejnych 3 min skrawania parametr $R a$ jest 4 razy większy od wartości początkowej. Tak dużych zmian chropowatości nie zaobserwowano ani dla głębokości skrawania $a_{p}=0,15 \mathrm{~mm}$, ani dla $a_{p}=0,1 \mathrm{~mm}$. Rozstęp wyników parametru chropowatości $R a$ (dla każdej wartości dosuwu $a_{p}$ ) zawiera się w przedziale $R a \pm 0,05 \mu \mathrm{m}$.

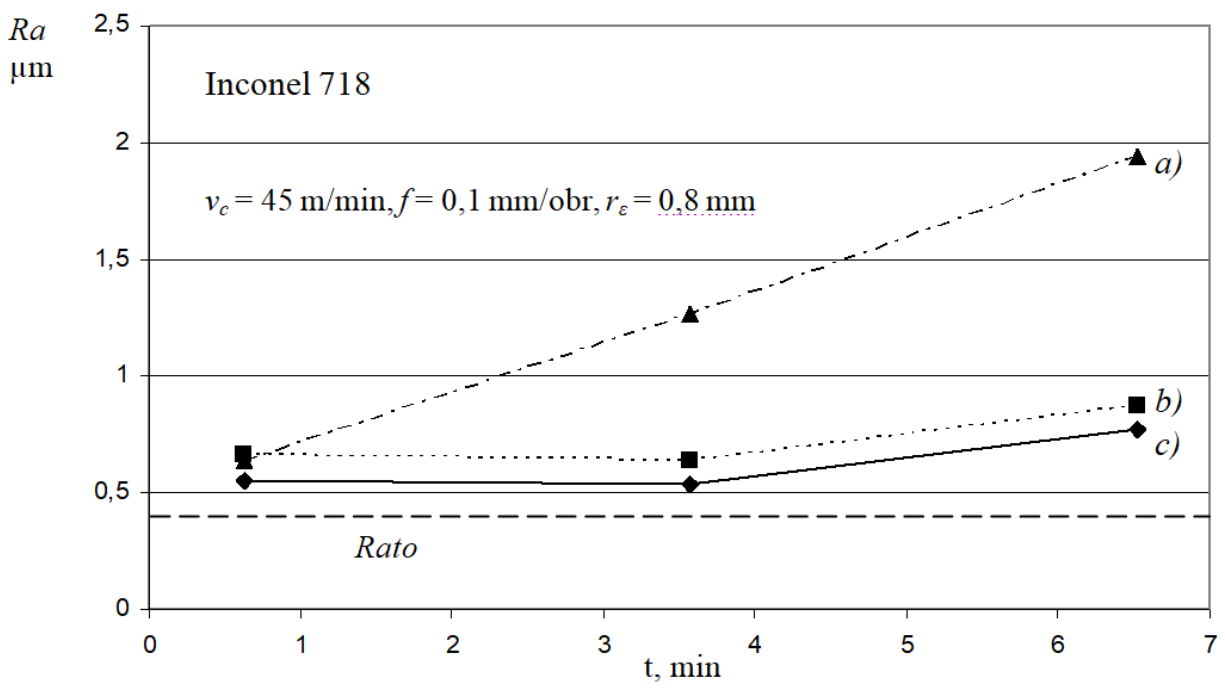

Rys. 3. Zależność parametru chropowatości $R a$ od czasu skrawania po wytaczaniu dla różnych głębokości skrawania $a_{p}$ : a) $a_{p}=0,4 \mathrm{~mm}$, b) $a_{p}=0,15 \mathrm{~mm}$, c) $a_{p}=0,1 \mathrm{~mm}$

Fig. 3. Dependence of roughness parameter $R a$ from the cutting time after boring at various cutting depths $a_{p}$ : a) $a_{p}=0.4 \mathrm{~mm}$, b) $a_{p}=0.15 \mathrm{~mm}$, c) $a_{p}=0.1 \mathrm{~mm}$

Na rysunku 4 przedstawiono przebieg zależności parametru chropowatości $R a$ od czasu skrawania podczas toczenia Inconelu 718 płytką z węglika spiekanego DCGT 11T308-UM S05F średnicy wewnętrznej i zewnętrznej. Przy zastosowanych takich samych parametrach skrawania otrzymano dwie różne funkcje $R a=\mathrm{f}(t)$. Podczas obróbki otworu funkcja ta jest monotonicznie rosnąca, natomiast podczas skrawania materiału na średnicy zewnętrznej funkcja ta jest monotonicznie malejąca. Większa chropowatość w otworze przy dosuwie $a_{p}=0,4 \mathrm{~mm}$ W porównaniu z chropowatością uzyskaną przy $a_{p}=0,15 \mathrm{~mm} \mathrm{i} a_{p}=0,1 \mathrm{~mm}$ (rys. 3) sugeruje, że jest to wynik szybszego zużycia ostrza. Uzyskana chropowatość podczas toczenia średnicy zewnętrznej przy takim samym dosuwie $a_{p}=0,4 \mathrm{~mm}$ (rys. 4) podważa jednak tę tezę. Pogorszenia jakości powierzchni w otworze przy $a_{p}=0,4 \mathrm{~mm}$ należy się więc doszukiwać w uszkodzeniu jej przez kłębiące się wióry (rys. 5). Teza ta (podobnie jak przy wierceniu) potwierdza, że bardzo istotne staje się odprowadzenie wiórów z przestrzeni roboczej. 


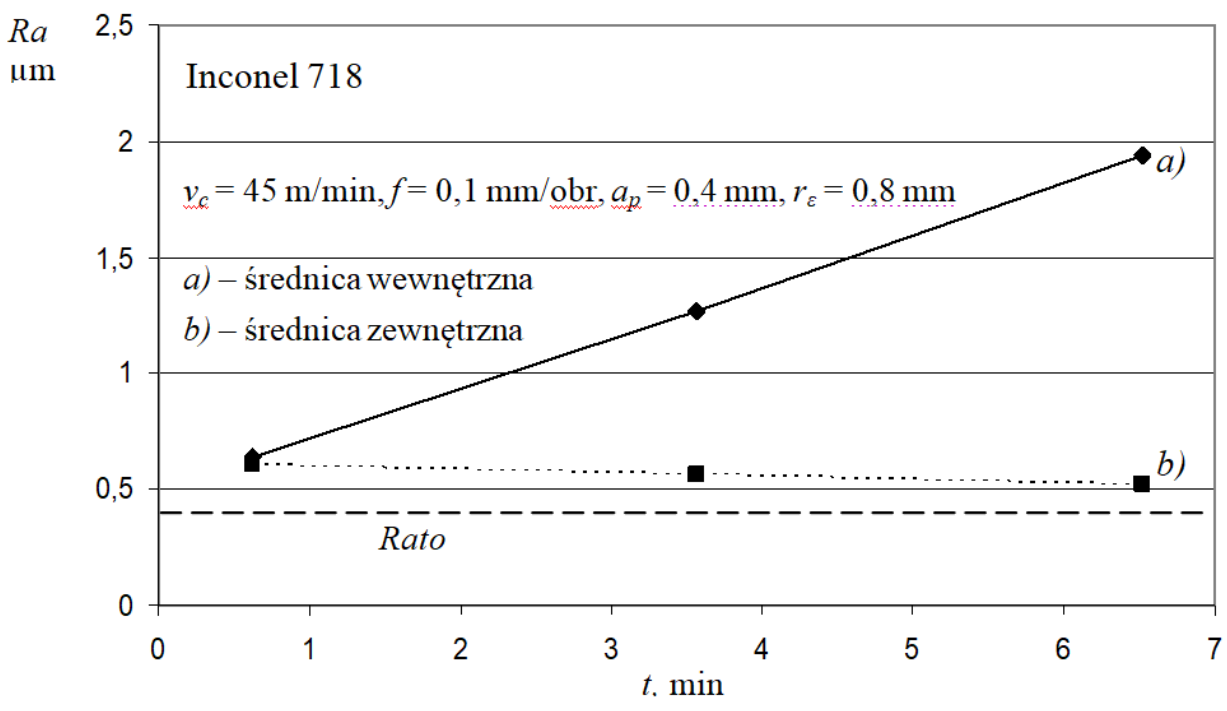

Rys. 4. Zależność parametru chropowatości $R a$ od czasu skrawania po wytaczaniu i toczeniu stopu Inconel 718: a) średnica wewnętrzna, b) średnica zewnętrzna

Fig. 4. Dependence of roughness parameter $R a$ from the cutting time after boring and turning Inconel 718 alloy: a) inside diameter, b) outside diameter

Rys. 5. Wióry po wytaczaniu Inconelu 718 płytką z węglika spiekanego z powłoką S05F: $v_{c}=45 \mathrm{~m} / \mathrm{min}, f=0,1$ $\mathrm{mm} / \mathrm{obr} ., a_{p}=0,4 \mathrm{~mm}$

Fig. 5. Chips after boring of Inconel 718 by carbide insert with $\mathrm{S} 05 \mathrm{~F}$ coating: $v_{c}=45 \mathrm{~m} / \mathrm{min}, f=0.1 \mathrm{~mm} / \mathrm{rev} ., a_{p}=0.4$ $\mathrm{mm}$

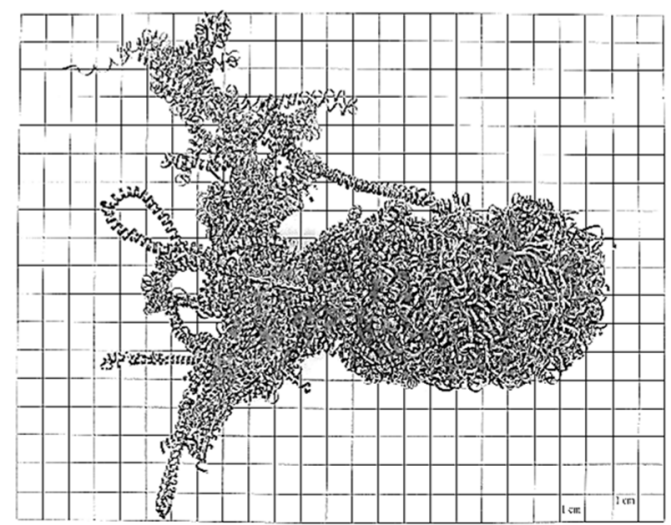

Rysunek 6 przedstawia objawy zużycia ostrza na powierzchni natarcia ostrza z węglika spiekanego powlekanego S05F po wytaczaniu Inconelu 718 przy różnych wartościach dosuwu $a_{p}$. Z kolei na rysunku 7 przedstawiono objawy zużycia tego samego ostrza na powierzchni przyłożenia. Większe zużycie ostrza zarówno na powierzchni natarcia, jak i na powierzchni przyłożenia zaobserwowano dla dosuwu $a_{p}=0,4 \mathrm{~mm}$. Duży wpływ na taką sytuację ma ilość wytworzonych wiórów, która dla $a_{p}=0,4 \mathrm{~mm}$ jest znacznie większa, a kłębiące się wióry (rys. 5) utrudniają dokładne doprowadzenie cieczy chłodząco-smarującej do 

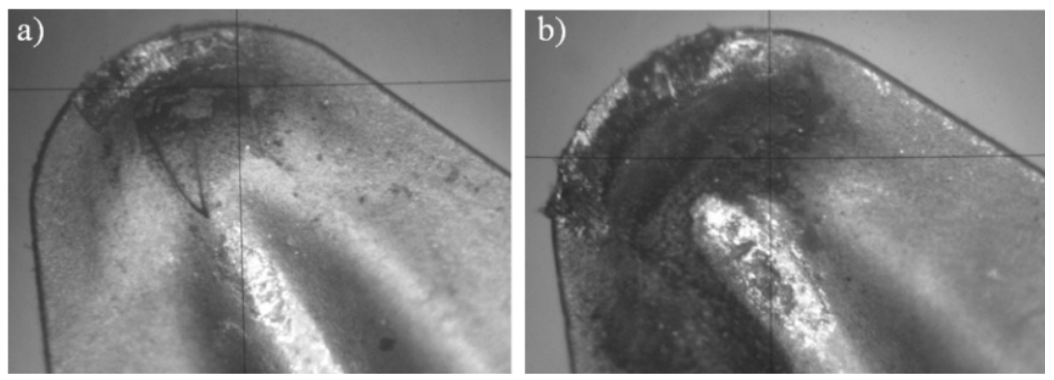

Rys. 6. Objawy zużycia ostrza z węglika spiekanego na powierzchni natarcia po wytaczaniu $-v_{c}=45 \mathrm{~m} / \mathrm{min}, f=0,1 \mathrm{~mm} / \mathrm{obr} .:$ a) $a_{p}=0,1 \mathrm{~mm}$, b) $a_{p}=0,4 \mathrm{~mm}$

Fig. 6. Symptoms of carbide insert's wear on the rake face after boring at $v_{c}=45$ $\mathrm{m} / \mathrm{min}$ and $f=0.1 \mathrm{~mm} / \mathrm{rev} .:$ a) $\left.a_{p}=0.1 \mathrm{~mm}, \mathrm{~b}\right) a_{p}=0.4 \mathrm{~mm}$
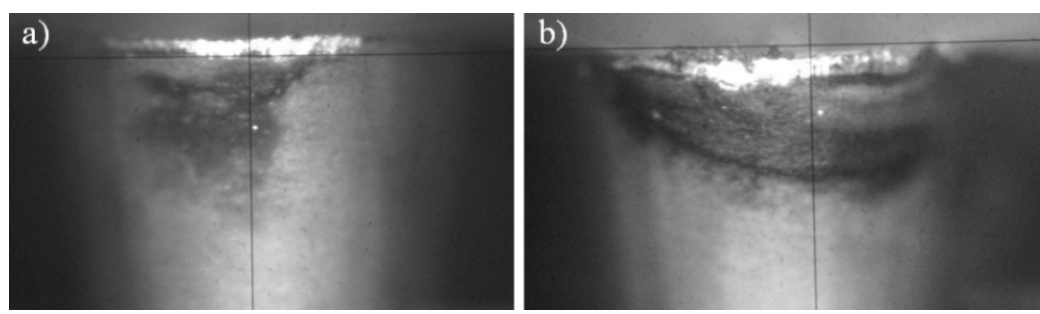

Rys. 7. Objawy zużycia ostrza z węglika spiekanego na powierzchni przyłożenia po wytaczaniu $-v_{c}=45 \mathrm{~m} / \mathrm{min}, f=0,1 \mathrm{~mm} / \mathrm{obr}$.: a) $a_{p}=0,1 \mathrm{~mm}$, b) $a_{p}=0,4 \mathrm{~mm}$

Fig. 7. Symptoms of carbide insert's wear on the flank face after boring at $v_{c}=45$ $\mathrm{m} / \mathrm{min}$ and $f=0.1 \mathrm{~mm} / \mathrm{rev} .:$ a) $\left.a_{p}=0.1 \mathrm{~mm}, \mathrm{~b}\right) a_{p}=0.4 \mathrm{~mm}$
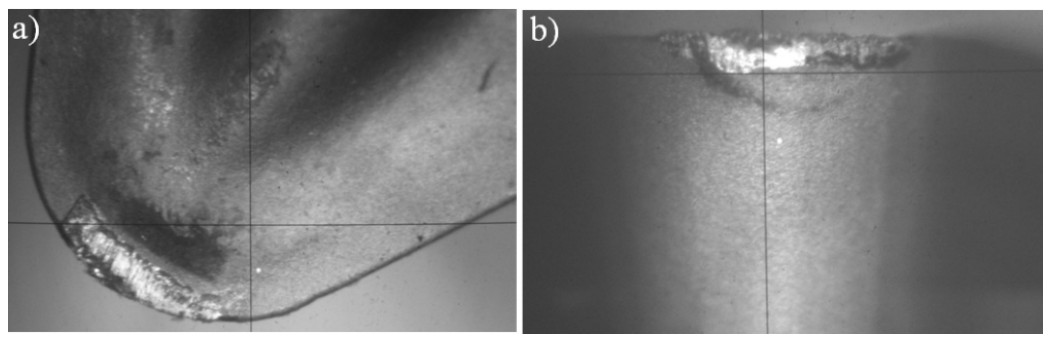

Rys. 8. Objawy zużycia ostrza z węglika spiekanego na powierzchni natarcia i przyłożenia po toczeniu Inconelu $718-v_{c}=45 \mathrm{~m} / \mathrm{min}, f=0,1 \mathrm{~mm} / \mathrm{obr} .: a_{p}=0,4 \mathrm{~mm}$, b) $a_{p}=0.4 \mathrm{~mm}$

Fig. 8. Symptoms of carbide insert's wear on the rake face and flank face after turning Inconel 718 at $v_{c}=45 \mathrm{~m} / \mathrm{min}$ and $f=0.1 \mathrm{~mm} / \mathrm{rev}$ :: a) $a_{p}=0.1 \mathrm{~mm}$, b) $a_{p}=0.4 \mathrm{~mm}$

strefy skrawania. W celu przedstawienia różnic objawów zużycia podczas toczenia i wytaczania Inconelu 718 na rys. 8 pokazano objawy zużycia ostrza $\mathrm{z}$ węglika spiekanego powlekanego S05F po toczeniu z dosuwem $a_{p}=0,4 \mathrm{~mm}$. 
Mniejsze zużycie na powierzchni natarcia i przyłożenia podczas toczenia w porównaniu ze zużyciem ostrza po wytaczaniu z tą samą głębokością skrawania potwierdza konieczność dokładnego doprowadzenia cieczy chłodząco-smarującej do strefy skrawania.

\section{Podsumowanie}

Chropowatość powierzchni obrobionej podczas wytaczania materiału Inconel 718 w dużym stopniu zależy od głębokości skrawania. Większa głębokość skrawania utrudnia możliwość dostarczenia cieczy chłodząco-smarującej do strefy skrawania. Powodem tego są kłębiące się wióry, które w przypadku tego materiału są trudne do złamania. Chropowatość powierzchni obrobionej podczas wytaczania dość szybko zmienia się w czasie. Jej wartość po 6 min obróbki jest 4 razy większa. Takiej sytuacji nie zaobserwowano podczas toczenia średnicy zewnętrznej, gdzie wiór nie ogranicza ilości cieczy chłodząco-smarującej dostarczanej podczas procesu obróbki.

\section{Literatura}

[1] Alauddin M., El-Baradie M.A., Hashmi M.S.J.: Optimization of surface finish in end milling Inconel 718, J. Mat. Pro. Technol., 56 (1996) 54-65.

[2] Aronson R.B.: What's different about manufacturing for Aerospace?, Manuf. Eng., 126 (2002) 36-38.

[3] Jawaid A., Koksal S., Sharif S.: Cutting performance and wear characteristics of PVD coated and uncoated carbide tools in face milling Inconel 718 aerospace alloy, J. Mat. Pro. Technol., 116 (2001) 2-9.

[4] Jindal P.C., Santhanam A.T., Schleinkofer U., Shuster A.F.: Performance of PVD TiN, TiCN, and TiAlN coated cemented carbide tools in turning, Int. J. Refractory Metals Hard Materials, 17 (1999) 163-170.

[5] M’Saoubi R., Axinte D., Soo S.L., Nobel C., Attia H., Kappmeyer G., Engin S., Sim W.M.: High performance cutting of advanced aerospace alloys and composite materials, CIRP Annals - Manuf. Technol., 64 (2015) 557-580.

\section{STUDY OF EFFECT OF THE CUTTING DEPTH ON SURFACE ROUGHNESS OF INCONEL 718 ALLOY DURING FINISH TURNING}

\section{S u m m a r y}

The aim of this study was to determine the impact of the depth of cut while boring a hole in the Inconel 718 on the roughness of the machined surface. The surface roughness after longitudinal turning and boring at comparable conditions were also measured. The obtained results indicated the meaningfulness of the application of lower cutting depth values, due to the faster wear of the cutting edge, which is directly affected by limited cooling in the cutting zone. With unfavorable conditions while boring, the cutting edge wears faster, resulting in deterioration in the quality of the work surface. The limited amount of cutting fluid in the cutting zone is the result of curling of chips, which, in the case of small workpiece diameters, are difficult to remove from the workpiece. The 
same parameters used in the trial where the highest roughness was obtained were applied during longitudinal turning. In this case, the free-flow chip after the machined part did not limit the amount of coolant supplied in the cutting zone, resulting in less cutting edge wear and less surface roughness.

Keywords: tool life, microroughness, chips

DOI: $10.7862 / \mathrm{rm} .2017 .51$

Przestano do redakcji: 14.08 .2017

Przyjęto do druku: 18.10 .2017 